\title{
The Action Mechanism of Social Exchange Relationship Perception on Organizational Citizenship Behavior: An Empirical Study in China
}

\author{
Yanhan Zhu \\ School of Political Science and Public Management \\ Southwest University \\ Chongqing 400715, China \\ Tel: 86-18983799871Ｅ-mail: littleyan@yahoo.cn
}

Received: December 19, 2011

Accepted: January 16, 2012 Published: March 15, 2012

doi:10.5430/ijba.v3n2p84

URL: http://dx.doi.org/10.5430/ijba.v3n2p84

The research is sponsored by Humanity and Social Science Youth funds of Ministry of Education "Study on the Effects of Exchange Relationship Perception on Individual Behavior"(2012) , "the Fundamental Research Funds for the Central Universities(SWU1209373)” and "Social Science Doctor Fund Program of Southwest University”"(SWU11333).

\begin{abstract}
Starting from the exchange relationship and according to the Stimulus-Organism-Response (S-O-R) model in dynamic psychology, this paper builds an action mechanism model of social exchange relationship and organizational citizenship behavior, taking the staff as the carrier, from the perspective of individual perception. Empirical studies show that affective job satisfaction has a steady and strong intermediary effect. Accordingly, the author proposes relevant suggestions for business management and practice.
\end{abstract}

Keywords: Social Exchange Relationship Perception, Affective Job Satisfaction, Organizational Citizenship Behavior

With the fast development of social economy and the deepening process of enterprises reform, the labor relations in enterprises that keep in dynamic evolvement and development have become one of important key entry points for researching and solving the contradictions in social economic relations. To interpret the labor relation based on social exchange relationship is a new perspective to understand the microscopic mechanism of labor relations in enterprises. "The God feel, then things grow; the saint perceives people's heart, then world is in peace." Since ancient times, the essence of management is about people. Perception, as the process in which employees select, evaluate, and organize the external stimulus (information), is a general term for employees' feelings and consciousness. It is the foundation for employees' psychological activities and behavioral responses. In view of this, taking the staff as the carrier and starting from the exchange relationship, this research tries to build an operational pattern for the dynamic individual labor relation, in the hope of presenting a most fundamental perspective based on human perception for the construction of harmonious labor relations.

\section{Literature Review and Hypothesis Deduction}

\subsection{The Social Exchange Relationship Perception and Employees' Individual Behavior}

A basic understanding of social exchange relationship is that the relationship can evolve into a trust, loyalty, and mutual commitment as time goes on. With this basis, two parties in the exchange relationship must adhere to certain "rules" of exchange, and these rules virtually become the normative definition of a variable of scene, which includes the two parties in the exchange relationship. To some extent, these rules of exchange can be regarded as guidelines and principles for the exchange process. Social exchange theory is a powerful analysis framework for understanding the relationship between employees and enterprises. It is a main conceptual paradigm to understand the employee behaviors in work place (Cropanzano \& Mitchell, 2005). Social exchange relationship may evolve into a trust, loyalty, and mutual commitment. Its basic principles include the principle of reciprocity, the principle of collective benefit, the principle of identity consistency, etc. Reviewing the development and evolvement of social exchange theory, studies on social exchange relationships change from the description of objective existence and develop into the differentiate interpretation based on individual perception. "There is nothing but matters, lives, and souls in the universe. The 
so-called theorem and law also belong to the three kinds. Senses and knowledge are perceptions of the phenomenon." Perception, as "a process of individuals selecting, assessing, and organizing external stimulus (information)", in Modern Chinese Dictionary, is a reflection, namely a direct reflection of objective matters in human brains by sensitive organs. As a philosophical term, perception refers to sensation and knowledge. Reviewing the researches of exchange relationship, the academic field witnesses the development process from a discussion of exchange forms, to an exploration of exchange contents, and to the presentation of exchange relationship perception. The exchange relationship perception, as a new independent concept, was officially proposed by Journal of Management, an authority academic journal in America, in 2009. The social exchange relationship perception refers to employees' perception of the implicit contract relationship between employees and enterprises based on social affective benefit and trust. The implicit contract focuses on the long-term open exchange of contents. The core principle of exchange is reciprocity. The exchange is based on trust. Social psychology emphasizes that perception can induce the generation of behavior. John B. Watson, an American psychologist and the founder of behaviorism, pointed out that "all human and animal behaviors could be decomposed into stimulus and response". He proposed the famous "Stimulus-Response (S-R)" mode. The exchange relationship between employees and enterprises, like a stimulus, affects the employee and makes him or her generate a particular perception, thus inducing the production of specific behaviors. In enterprises, employees play different roles (such as the role of decision-maker, the role of coordinator, etc.) according to their positions. Organizational citizenship behavior is the sum of employees' spontaneous behaviors that benefit the operational efficiencies of enterprises in general but not be recognized clearly or directly by the formal salary system. Accordingly, this research makes the following hypotheses.

Hypothesis 1: There is a positive correlation between employees' social exchange relationship perception and organizational citizenship behavior.

\subsection{The Intermediary Effect of Affective Job Satisfaction}

Job satisfaction, as a production of non-regulatory emotional orientation, was initially defined by Fisher and Hanna (1931) as work-related affective state, including five dimensions: boss, job, coworkers, pay, and promotion prospects. Job satisfaction, as a pleasant or positive affective state, grows from the process employees assessing their job experiences. Affective job satisfaction is an overall positive affective assessment of the job. It cares about whether the job stimulates employees' pleasant affections and positive feelings. Employees' perception of enterprises' management style and their feelings for interpersonal relationships can impact on the generation of employees' job satisfaction, while job satisfaction has a direct effect on individual behaviors, such as absenteeism, violation behaviors in workplace, and leave. Woodworth, an American dynamic psychologist, developed the "S-R" mode based on psychology of behaviorism and proposed the well-known "S-O-R" mode, which indicates that there is an organism between stimulus and response, a "black box" changing stimulus into response. Accordingly, this research assumes that affective job satisfaction is the converter between stimulus and response, being an intermediary bridge between employees' exchange relationship perception and individual behavior, and makes the following hypothesis:

Hypothesis 2: Affective job satisfaction plays an intermediary and conductive role in employees' exchange relationship perception and organizational citizenship behavior.

\section{Design of the Research}

\subsection{Construct Definitions and Scale Selection}

(1) Social Exchange Relationship Perception (SERP): employees' perception of the implicit contract relationship between employees and enterprises based on social affective benefit and trust. The implicit contract focuses on the long-term open exchange of contents. The core principle of exchange is reciprocity. The exchange is based on trust.

(2) Organizational Citizenship Behavior (OCB): the sum of employees' spontaneous behaviors that benefit the operational efficiencies of enterprises in general but not recognized clearly or directly by the formal salary system.

(3) Affective Job Satisfaction (AJS): individuals' positive assessment of their job circumstances (Weiss, 2002). Individuals can make overall affective assessments of their job circumstances by "like" or "dislike" and relevant degrees.

\subsection{Common Method Bias Test}

This research uses Harman's single-factor test. Firstly make factor analysis of all significant variables in SPSS17.0 and get 19 factors under the condition of greater-than-one eigenvalue and without any rotation. The contribution rate of largest factor is $17.769 \%$, far less than $50 \%$, which can be considered in this research there is no common method bias problem. 


\subsection{Reliability Test and Validity Test}

Table 2 shows that after the pre-testing of the scale and pre-processing of data, the reliability index $\mathrm{R}^{2}$ of all significant variables is greater than 0.50 . It means the variability of individual observed variable is greater than $1 / 2$. Meanwhile, the combined reliability CR of all construct concepts is greater than 0.80 , which means better combined reliability of construct concept and Cronbach $\alpha$ is greater than 0.70. To sum up, the questionnaire of the research has good reliability.

The convergent validity results in Table 3 shows that the AVE of social exchange relationship perception is 0.52 , the AVE of affective job satisfaction is 0.56 , and the AVE of organizational citizenship behavior is 0.61 , which means that these construct concepts have good convergent validity.

\section{Hypothesis Test and Research Results}

This research delivered 632 copies of questionnaires by enterprise field survey, online platform, mail, and "snowball" way in Sichuan, Yunnan, Guizhou, Zhejiang, Shanghai, and Beijing, and finally collected 581 valid questionnaires.

\subsection{Main Effect Test}

Table 5 shows that under the circumstance of the good overall goodness of fit of the model, the path analysis of structural equation model indicates that there is a statistical significant positive correlation between employees' social exchange relationship perception and organizational citizenship behavior in the $99 \%$ reliability range. H1 is supported.

\subsection{Intermediary Effect Test}

Table 6 shows that the overall goodness of fit of the model is good. According to the intermediary effect test proposed by Baron and Kenny and the Sobel test, affective job satisfaction plays a complete intermediary role in employees' social exchange relationship perception and organizational citizenship behavior. $\mathrm{H} 2$ is supported.

\section{Management Implication}

(1) Build supportive human resource management practice, establish and maintain the social exchange relationship with employees, and enhance employees' social exchange relationship perception. Human resource management practice reflects the enterprise's intention. Employees take it as a practical signal, indicating whether the enterprise regards them as capitals or tools. It is the basis of inducing employees' response behaviors. Supportive human resource management practice insists on the management strategy exchanging duty by duty, flexibility by ability, enhancing employees' commitment to organization by high-performance work system, maintaining and strengthening the dynamic individual labor relations between employees and enterprise. By building an "investment" human resource management practice, make employees truly feel that enterprises take them as resources, instead of tools for collecting interests. Enterprises are willing to invest in the development of employees' career, which can strongly promote the long-term open exchange mode based on social affective interests ------ the long-term development of social exchange relationship between employees and enterprises. Meanwhile, build the people-oriented enterprise culture and improve employees' affective job satisfaction.

(2) Construct cooperative labor relations between employees and enterprises. As the collection of team production factors, the survival and development of enterprises depends on an organic integration of various production factors. In the mutual game of human resource capitals and material capitals, the win-win situation is the key for creating and maintaining the value of enterprises. To actively build a cooperative relation enables the enterprise get a sustainable competitive advantage. Cooperative labor relations are the employment relationships based on the self-conscious cooperative willingness of the subjects in labor relations. The enterprise develops and implements labor relations strategy based on the principle of "reciprocity". Employees and the enterprise make efforts to achieve the common goal and their own interests. In cooperative labor relations, the labor union should play its real role. The management believes that the labor union is willing to cooperate with the management (employers) to reduce production costs. The management (employers) is willing to allow the labor union to participate in the daily business operation. The labor union will encourage the staff (employees) to improve the labor productivity, seeking more tangible or intangible benefits for the staff (employees). The two sides decide the problems in production (even in distribution of interests) together, continuously improving the business efficiency. At last, form the stable, win-win, cooperated-developing labor relations.

(3) Build the people-oriented enterprise culture and improve employees' affective job satisfaction. Affective job satisfaction has a tempting and driving effect on employees spontaneously conducting pro-business behaviors. Differing from cognitive job satisfaction, the construction of affective job satisfaction focuses on the enterprise's general emotional input in employees. To build the people- oriented enterprise culture is an effective way of improving employees' affective job satisfaction. Enterprise culture is a series of values and value system commonly held by 
employees. Enterprise culture has two layers, namely the surface and the core. The surface enterprise culture is displayed by exterior things, such as ceremony, language, and closes. The core enterprise culture is the norms and values reflected by the surface enterprise culture. The performance-oriented enterprise culture can achieve excellent performance but may kill the motive for healthy development. The "jumping tragedy" happened in Foxconn in 2010 slapped the "wolf culture" right in the face. The karoshi of employees in Huawei is a warning for the "mattress culture" that emphasizes too much on performance and innovation. To build a people-oriented enterprise culture that takes the growth of employees as the basis for the development of enterprise can improve employees' affective job satisfaction in a real sense. It is a real management practice for unifying people together and driving the harmonious development of enterprise.

(4) Pay attention to the internal labor market in the enterprise and use incentives to ensure the orderly development of enterprise. The internal labor market in the enterprise is the sum of all institutions about various labor contracts and employment arrangements. Concerns for enterprise's internal labor market can improve employees' senses of acceptance and affiliation, enhancing employees' loyalty to the enterprise. The pursuit for Pareto Optimality is the objective of enterprise's resource optimization. Compared to the external labor market, to emphasize on exploring the internal labor market has many advantages in sustainable development. Firstly, the internal labor market can fuel the human resource development. Along with the development of market economy, the stability and continuity of labor relationship become a practical issue demanding an urgent resolution. For the labor relationship in market, both enterprises and employees are not encouraged to invest more in human resources, while the internal labor market enhances the expectations for long-term labor relationship, establishing the basis for human resource investment. Secondly, the internal labor market can help to achieve the long-term incentive compatibility. By means of a set of long-term incentive mechanism, such as job ladder and internal promotion system, and seniority-oriented pay system, the enterprise can guarantee the long-term dynamic operation efficiency.

\section{Reference}

Allen, D. C., Shore, L. M. \& Griffeth, R. W. (2003). The role of perceived organizational support and supportive human resource practices in the turnover process [J]. Journal of Management, Vol.29: 99-118, doi:10.1016/S0149-2063(02)00222-2, http://dx.doi.org/10.1016/S0149-2063(02)00222-2.

Ann, E. S., Tsui Jone, L., Pearce, L. W. Porter, \& Angela, M. T. (1997). Alternative approaches to the employee-organization relationship: does investment in employees pay off? Academy of Management Journal, Vol.40:108.

Babin, B. J., \& Boles, J. S. (2002). The effects of perceived co-worker involvement and supervisor support on the service provider role stress, performance and job satisfaction [J]. Journal of Retailing, Vol. 72, pp. 57-75, doi:10.1016/S0022-4359(96)90005-6, http://dx.doi.org/10.1016/S0022-4359(96)90005-6.

Conway, J. M. \& Lance, C. E. (2010). What reviewers should expect from authors regarding common method bias in organizational research [J]. Journal of Business \& Psychology, Vol.25: 325-334, doi:10.1007/s10869-010-9181-6, http://dx.doi.org/10.1007/s10869-010-9181-6.

Duanxu W., Anne, S. Tsui Yichi, Z. \& Li, M. (2003). Employment relationships and firm performance: evidence from an emerging economy [J]. Journal of Organizational Behavior, Vol.24:511-535.

Francis, J. F. (2005). Identity orientations and forms of social exchange in organizations [J]. Academy of Management Review, Vol.30:737-750.

Jacqueline A. M. C. \& Lynn, M. S. (2007). The employee-organization relationship: where do we go from here? [J]. Human Resource Management Review, Vol. 17:166-179.

Jacqueline, A. M. C. \& Neil, C. (2004). The employment relationship through the lens of social exchange. The Employment Relationship: Examining Psychological and Contextual Perspectives. Oxford University.

Lunderen, S. M., Nordholm, L. \& Segesten, K. (2005). Job satisfaction in relation to change to all RN staffing [J]. Journal of Nurse Management, Vol.13:322-328.

Lynda, J. S., Anne S. T. \& Kenneth, S. L. (2009). Unpacking employee responses to organizational exchange mechanisms: the role of social and economic exchange perception? [J]. Journal of Management, Vol.35: 56-93.

Shore, L. M., Tetrick, L. E., Lynch, P. \& Barksdale, K. (2006). Social and economic exchanges: construct development and validation [J]. Journal of Applied Social Psychology, Vol.36:837-867, doi:10.1111/j.0021-9029.2006.00046.x, http://dx.doi.org/10.1111/j.0021-9029.2006.00046.x. 
Table 1. The source of construct scale.

\begin{tabular}{|c|c|}
\hline Construct definition & Source of scale \\
\hline Social Exchange Relationship Perception (SERP) & Lynn M. Shore et al., 2006 \\
\hline Affective Job Satisfaction (AJS) & Timothy A. Judge et al., 2000 \\
\hline Organizational Citizenship Behavior (OCB) & Larry J. Williams \& Stella E. Anderson, 1991 \\
\hline
\end{tabular}

Table 2. Reliability test results

\begin{tabular}{|c|c|c|c|c|c|c|c|c|c|}
\hline Construct definition & Item & $R^{2}$ & $\mathrm{CR}$ & $\alpha$ & Construct definition & Item & $R^{2}$ & $\mathrm{CR}$ & $\alpha$ \\
\hline \multirow{7}{*}{$\begin{array}{c}\text { Social Exchange } \\
\text { Relationship } \\
\text { Perception } \\
\text { (SERP) }\end{array}$} & SERP1 & 0.565 & 0.87 & 0.77 & \multirow{4}{*}{$\begin{array}{l}\text { Organizational } \\
\text { Citizenship } \\
\text { Behavior } \\
\text { (OCB) }\end{array}$} & OCB 3 & 0.639 & & \\
\hline & SERP2 & 0.534 & & & & $\overline{\mathrm{OCB}} 4$ & 0.586 & & \\
\hline & SERP3 & 0.536 & & & & OCB 5 & 0.804 & & \\
\hline & SERP4 & 0.664 & & & & OCB 6 & 0.846 & & \\
\hline & SERP5 & 0.789 & & & \multirow{5}{*}{$\begin{array}{l}\text { Affective Job } \\
\text { Satisfaction } \\
\text { (AJS) }\end{array}$} & AJS1 & 0.518 & 0.85 & 0.82 \\
\hline & SERP6 & 0.689 & & & & AJS2 & 0.559 & & \\
\hline & SERP7 & 0.687 & & & & AJS3 & 0.546 & & \\
\hline \multirow[t]{2}{*}{ OCB } & OCB 1 & 0.736 & 0.87 & 0.85 & & AJS4 & 0.753 & & \\
\hline & OCB 2 & 0.862 & & & & AJS5 & 0.546 & & \\
\hline
\end{tabular}

Table 3. Convergent validity test results

\begin{tabular}{|l|c|c|c|}
\hline \multirow{2}{*}{$\begin{array}{c}\text { Average Variance } \\
\text { Extracted (AVE) }\end{array}$} & $\begin{array}{c}\text { Social Exchange Relationship } \\
\text { Perception(SERP) }\end{array}$ & $\begin{array}{c}\text { Affective Job Satisfaction } \\
\text { (AJS) }\end{array}$ & $\begin{array}{c}\text { Organizational Citizenship } \\
\text { Behavior (OCB) }\end{array}$ \\
\cline { 2 - 4 } & 0.52 & 0.56 & 0.61 \\
\hline
\end{tabular}

Table 4. Discriminate validity test results

\begin{tabular}{|c|c|c|c|}
\hline & $\begin{array}{c}\text { Social Exchange Relationship } \\
\text { Perception(SERP) }\end{array}$ & $\begin{array}{c}\text { Affective Job } \\
\text { Satisfaction (AJS) }\end{array}$ & $\begin{array}{c}\text { Organizational Citizenship } \\
\text { Behavior (OCB) }\end{array}$ \\
\hline Social Exchange Relationship Perception(SERP) & 0.72 & $0.482(* *)$ & $0.172(* *)$ \\
\hline Affective Job Satisfaction (AJS) & & 0.75 & $0.134(* *)$ \\
\hline Organizational Citizenship Behavior (OCB) & & & 0.78 \\
\hline
\end{tabular}

Notice: The diagonal of matrix is the square root of AVE. The correlation coefficient of variables is above the diagonal.

$* \mathrm{P}<0.05$ (2-tailed); ** $\mathrm{p}<0.01$ (2-tailed)

Table 5. Main effect test results analysis

\begin{tabular}{|c|c|c|c|c|}
\hline Hypothesis path & $\begin{array}{l}\text { Regression } \\
\text { coefficient }\end{array}$ & $\begin{array}{c}\text { Standard regression } \\
\text { coefficient }\end{array}$ & $\mathrm{t}$ & $\begin{array}{c}\text { Support the } \\
\text { hypothesis or not }\end{array}$ \\
\hline $\begin{array}{l}\text { H1: Social exchange relationship perception } \\
\text {-----Organizational Citizenship Behavior }\end{array}$ & 0.225 & 0.37 & $5.208(* * *)$ & Support \\
\hline \multicolumn{5}{|c|}{$\begin{aligned} & \text { Goodness of fit: } \quad \chi^{2} / d f=2.2 ; \mathrm{RMSEA}=0.046 ; \mathrm{RMR}=0.041 ; \mathrm{GFI}=0.95 ; \\
& \mathrm{IFI}=0.958 ; \mathrm{RFI}=0.91 ; \mathrm{PNFI}=0.75 ; \mathrm{PGFI}=0.689\end{aligned}$} \\
\hline
\end{tabular}

Notice: $* * * \mathrm{p}<0.001$ 
Table 6. Intermediary effect test results

\begin{tabular}{|c|c|c|c|c|}
\hline \multicolumn{5}{|c|}{ Intermediary effect test of affective job satisfaction } \\
\hline Hypothesis path & Standard regression coefficient & C.R (t) & S.E & P \\
\hline $\begin{array}{c}\text { Social exchange relationship perception } \\
---- \text { Affective job satisfaction }\end{array}$ & (a) 0.593 & 10.023 & 0.059 & $* * *$ \\
\hline $\begin{array}{c}\text { Affective job satisfaction } \\
---- \text { Organizational citizenship behavior }\end{array}$ & (b2) 0.267 & 4.711 & 0.057 & $* * *$ \\
\hline $\begin{array}{c}\text { Social exchange relationship perception } \\
---- \text { Organizational citizenship behavior }\end{array}$ & (c2) 0.041 & 1.082 & 0.037 & 0.279 \\
\hline $\begin{array}{l}\text { Goodness of fit: } \chi^{2} / d f=2.440 ; \text { RMSEA }=0.05 ; \text { RMR }=0.044 ; \text { GFI }=0.947 ; \\
\text { IFI }=0.961 ; \text { RFI }=0.921 \text { PNFI }=0.764 ; \text { PGFI }=0.687\end{array}$ \\
\hline
\end{tabular}

Notice: $* * * p<0.001$ 